EESTI NSV TEADUSTE AKADEEMIA TOIMETISED 1955. IV kd., nr. 2 ИЗВЕСТИЯ АКАДЕМИИ НАУК ЭСТОНСКОИ ССР 1955. Том IV, № 2

\title{
НОРМА СТОКА РЕК ЭСТОНСКОЙ ССР
}

\author{
В. А. ИОНАТ,
}

кандидат технических наук

Под нормой годового стока понимается средний размер годового стока за многолетний период. Для получения устойчивого значения нормы необходимо иметь около $35-40$ лет наблюдений. Ввиду того, что точное определение нормы стока возможно только при неограниченно большом числе $N$ лет наблюдений, размер нормы, определяемой как среднее арифметическое при ограниченном числе $n$ лет, отличается от истинного ее значения на величину $\pm \sigma$ - средней квадратичной ошибки, которая зависит от числа лет наблюдений и коэффициента вариации рядов годового стока.

Исследования Б. Д. Зайкова и С. Ю. Белинкова (') показали, что для решения вопроса о возможных погрешностях при вычислении нормы годового стока в зависимости от длины и изменчивости исходного ряда можно применить закон распределения случайных ошибок, согласно которому кривая распределения ошибок имеет симметричный вид.

Для рек Эстонской ССР коэффициент вариации рядов среднего годового стока колеблется в пределах от 0,25 до 0,40 . Размер ошибок, соответствующих приведенным коэффициентам вариации годовых значений стока при различной продолжительности рядов наблюдений, по Б. Д. Зайкову и С. Ю. Белинкову, приводится в таблице 1.

Таблица 1

\begin{tabular}{c|r|r|r|r|r|r|r|r}
\hline \multirow{2}{*}{$C_{v}$} & \multicolumn{6}{|c|}{ Число лет наблюдений при точности (в \%) } \\
\cline { 2 - 9 } & 4 & 5 & 6 & 7 & 8 & 9 & 10 & 20 \\
\hline & & & & & & & & \\
0,25 & 39 & 25 & 17 & 18 & 10 & 8 & 6 & 2 \\
0,30 & 56 & 36 & 25 & 19 & 14 & 11 & 9 & 2 \\
0,35 & 76 & 49 & 33 & 25 & 19 & 15 & 12 & 3 \\
0,40 & 100 & 64 & 44 & 33 & 25 & 20 & 16 & 4 \\
\end{tabular}

Необходимо заметить, что максимальная ошибка в определении размеров нормы может быть в 2-2,5 раза больше средней.

Как видно из таблицы, пользование коротким рядом дает значительные ошибки при определении нормы стока, так как в этом случае в ряд могут попасть данные, относящиеся в основном к многоводному или только к маловодному периоду. 
Определение нормы стока имеет большое практическое значение, так как норма стока является устойчивой гидрологической характеристикой данного района. Как указывает Д. Л. Соколовский, норму годового стока можно назвать гидрологическим эталоном или гидрологическим репером данного района, служащим исходной характеристикой для расчетов других характеристик стока. Если при изменении климатических условий, в частности благодаря деятельности человека, изменяется средняя величина осадков и испарения, то изменится и норма годового стока. Но при относительно нензменных условиях норма стока является устойчивой гидроклиматической характеристикой, обусловленной свойственным данному географическому ландшафту соотношением тепла и влаги $\left({ }^{4}\right)$.

При современном положении вычисление нормы стока для рек Әстонской ССР на основании данных непосредственных гидрометрических измерений с достаточной для практики точностью возможно лишь для небольшого числа речных бассейнов, т. е. только там, где имеются ряды наблюдений стока продолжительностью в 25-30 лет.

На подавляющем же большинстве рек Эстонской ССР гидрометрические измерения систематически проводятся лишь в послевоенный период, и поэтому длительность большинства рядов не превышает 6-7 лет. Определение нормы стока для рек, не имеющих рядов длительных гидрометрических измерений, приходится производить косвенными методами (приведение к норме), дающими возможность определить норму стока с достаточной для практики точностью. Приемы, применяемые в данном случае, разработаны советскими гидрологами и применяются в практике гидрологических расчетов. Подробное описание существующих методов приведения к норме дано, например, в работе Д. Л. Соколовского $\left({ }^{3}\right)$.

История вопроса. Первые попытки определения размеров нормы стока рек Эстонской ССР относятся к 1930-1932 годам, когда К. Т. Хоммик под руководством А. А. Вельнера составил карту распределения среднего годового стока на территории Эстонии и опубликовал ее в Гидрологическом ежегоднике Гидрометеорологического бюро за 1930-1932 годы $\left({ }^{5}\right)$.

Ввиду отсутствия необходимых гидрометрических данных Хоммик и Вельнер построили карту на основании уравнения водного баланса, приняв за основу многолетние метеорологические наблюдения за осадками и вычисленную по формуле Э. М. Ольдекопа $\left({ }^{2}\right)$ величину испарения. При вычислении нормы стока средняя величина осадков была определена за период с 1886 по 1910 год (по данным Срезневского). Применявшаяся для определения средней многолетней величины испарения формула Э. М. Ольдекопа имеет следующий вид:

$$
z=\operatorname{ad} \text { th } \frac{x}{a d}
$$

где $a-$ постоянный коэффициент,

$x$ - среднее значение осадков за многолетний период,

$d$ - средний дефицит влажности за тот же период,

$z$ - испарение.

Составленная в 1932 году картограмма нормы стока, отражая влияние основных факторов, определяющих размеры среднегодового стока (осадки и испарение), не учитывала влияния ряда физнко-географических факторов, оказывающих существенное влияние на сток в ряде районов Эстонии. Так, например, в северных районах Эстонии имеет широкое распространение карст, который приводит к перераспределению подземного питания ряда речных бассейнов. Исследованиями Т. Ф. Эйпре, произведенным в связи с составлением схемы энергетического использования 
гидроресурсов Эстонской ССР, установлено, например, что норма стока реки Кунда должна быть увеличена на 5 л/сек $/ \mathrm{kм}^{2}$, т. е. почти на $70 \%$ по сравнению с данными картограммы Хоммика-Вельнера. Верховья реки Пярну также имеют увеличенное питание, которое обусловлено выходом ручьев карстового происхождения на Пандивереской возвышенности. Отдельные реки (р. Куйвайыги) проваливаются в карстовые воронки. Специфические особенности геологического строения четвертичных отложений северной и южной части Эстонской ССР также накладывают отпечаток на режим стока.

Перечисленные выше обстоятельства потребовали внесения поправок в карту Хоммика - Вельнера, которые и были произведены как Вельнером по данным наблюдений за стоком с 1929 по 1938 год, так и Әйпре.

Произведенные исправления несколько уточнили карту ХоммикаВельнера, не устранив, однако, основных ее недостатков.

В 1950 году, в связи с разработкой генеральной схемы мелиорации Эстонской ССР, была составлена карта нормы стока уже на основании гидрометрических данных. Составитель карты Н. П. Кулеш применил современную методику приводки к норме и получил довольно большое количество пунктов, по которым можно было составить карту среднего годового стока, К сожалению, к моменту составления карты на большинстве водпостов с короткими рядами наблюдений результаты наблюдений имелись лишь за $1-2$ года и поэтому получение достаточно надежных данных по ряду пунктов было затруднено, и эти пункты были исключены при составлении карты. Фактически карта была составлена только по 12 пунктам, причем 7 пунктов падали на бассейн Финского залива, 4 - на бассейн Чудского озера и только один пункт - на бассейн Рнжского залива.

Недостаточное количество пунктов, дажеке для условий незначительной по размеру территории Әстонской ССР, приводило к необходимости широкой интерполяции при построении карты, что явилось причиной недостаточной точности и этой карты.

К 1954 году положение в этом отношении значнтельно улучшилось, так как ряды наблюдений на всех водомерных постах значительно удлинились и появилась возможность получения более надежных данных. Использование данных по ряду новых пунктов позволяет определить норму стока большого количества мелких рек и получить в результате этого дополнительные пункты для более точного построения картограммы нормы стока.

Изученность стока и оценка исходных данных. Подсчет стока по отдельным водпостам Управления гидрометеорологической службы ЭССР (по состоянию на 1 I 1953) произведен за период от 3 до 46 лет. Наиболее продолжительные ряды измерений имеются по рекам Нарва (46 лет), Суур Әмайыги (35 лет) и Пярну (29 лет). Данные о чнсле пунктов и продолжительности периода наблюдений на них приводятся в таблице 2. Эта таблица показывает, что имеющийся в наличии гидрометрический материал в основном непригоден для непосредственного вычисления нормы стока, за исключением 8 пунктов, продолжительность наблюдений на которых превышает 25 лет. Для этих пунктов можно производить непосредственное вычисление нормы по средним годовым расходам, учитывая при этом, что средняя квадратичная ошибка при среднем коэффициенте вариации для Әстонской ССР $\left(C_{v}=0,35\right)$ составит $7-8 \%$. Указанная точность достаточна для гидрологических расчетов, и полученные данные можно считать приемлемыми для практического использования. 
Таблица 2

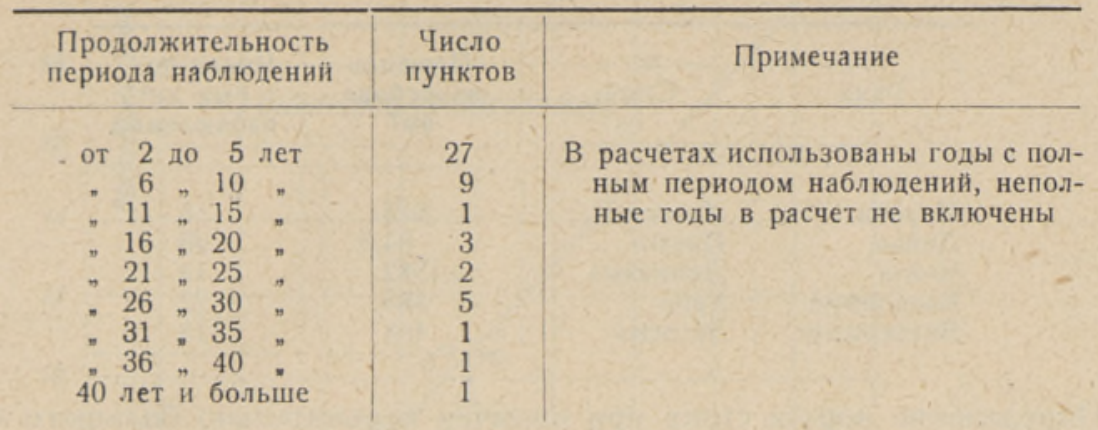

Приведение к норме. Выбор методики приведения к длинному ряду определялся в основном наличием и длиной рядов гидрометрических наблюдений. Для рек, по которым имелись достаточно длительные наблюдения, норма стока өпределялась непосредственным вычислением среднего многолетнего расхода. Для рек с короткими рядами наблюдений приводка производилась по связи среднегодовых или среднемесячных значений стока. Ввиду того, что распределение осадков по территории Әстонской ССР носит довольно пестрый характер и что, кроме того, сам метод приводки по осадкам дает менее точные результаты, было решено отказаться от указанного метода. Для западных островов (Сааремаа, Хийумаа) норма стока принята согласно данных приводки для пункта Метскюла на реке Пунапеа. В качестве основных опорных пунктов для приведения к норме использованы гтанции с продолжительностью рядов годовых наблюдений свыше 25 лет (таблица 3 )*.

Таблица 3

\begin{tabular}{c|c|c|c}
\hline Река & Створ & $\begin{array}{c}\text { Площадь } \\
\text { водосбора } \\
\text { км² }^{2}\end{array}$ & $\begin{array}{c}\text { Число полных } \\
\text { лет наблю- } \\
\text { дений }\end{array}$ \\
\hline
\end{tabular}

Пуртсе

Кейла

Пярну

Выханду

Вяйке Эмайыги

Суур Эмайыги
Бассейн Финского залива

\begin{tabular}{l|l} 
Люганусе & 792 \\
Кейла & 665
\end{tabular}

Бассейн Рижского залива

Орекюла $\mid 5180$

Бассейн Чудского озера

\begin{tabular}{l|r} 
Химмисте & 853 \\
Тыллисте & 1070 \\
Тарту & 7850
\end{tabular}

Наряду с основными опорными пунктами в качестве вспомогательных опорных пунктов для приведения коротких рядов были использованы пункты с продолжительностью наблюдений от 14 до 23 лет, после того как была уточнена их норма стока. Список вспомогательных опорных пунктов приводится в таблице 4 .

* Принимая во внимание незначительную разницу в длительности рядов аналогов, они не приводились к одному сроку наблюдений. 


\begin{tabular}{l|l|c|c}
\hline \multicolumn{1}{c|}{ Река } & Створ & $\begin{array}{c}\text { Площадь } \\
\text { водосбора } \\
\text { км² }\end{array}$ & $\begin{array}{c}\text { Число пол- } \\
\text { ных лет } \\
\text { наблюдений }\end{array}$ \\
\hline Пирита & Лагеди & 675 & 16 \\
Лейва & Паюба & 84,3 & 23 \\
Ягала & Линнамяэ & 1582 & 14 \\
Васалемма & Урба & 383 & 22 \\
Вихтерпалу & Энглема & 468 & 18
\end{tabular}

Определение нормы стока при наличии сравнительно большого числа лет наблюдений (свыше 10 лет) производилось по связи среднегодовых

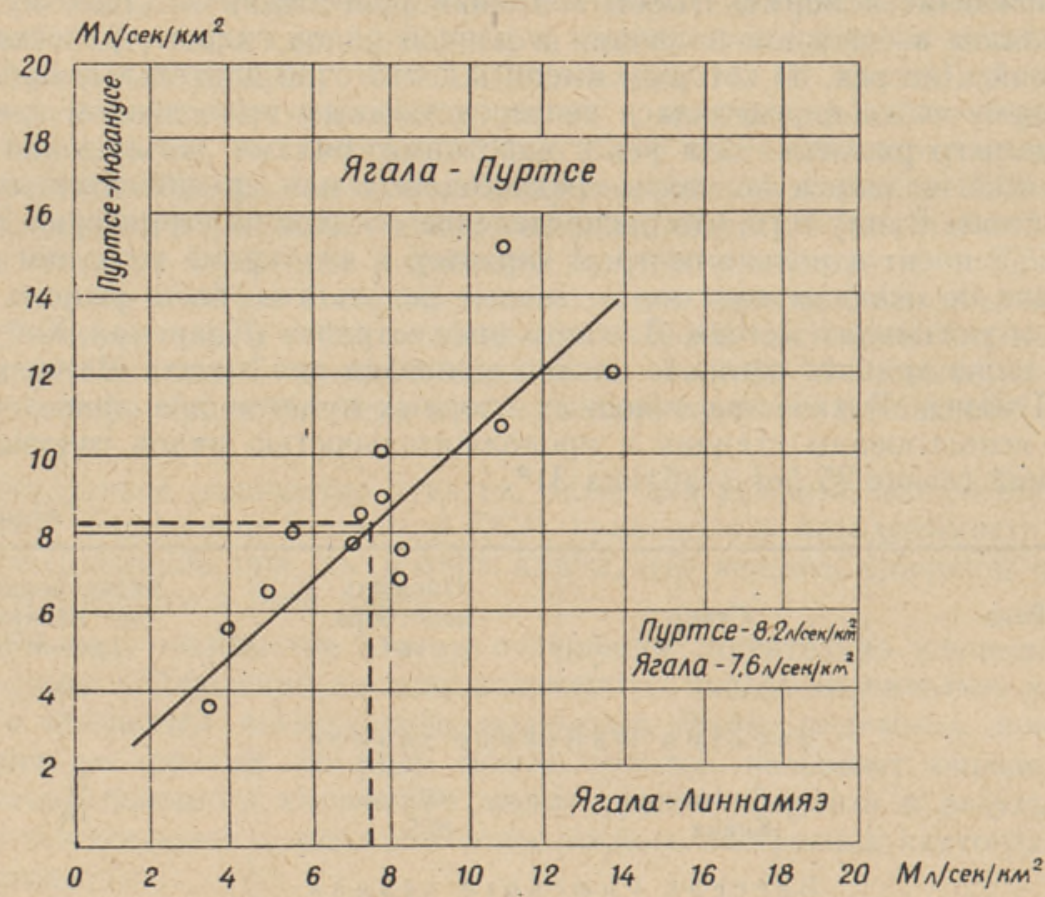

Рис. 1.

модулей стока (рис. 1,2 ). Короткие ряды (до 10 лет) приводились по среднемесячным значениям модулей стока (рис. 3,4 ). Приводка производилась во всех случаях графически, так как указанная методика дает более точные результаты, чем применяемый в некоторых случаях метод Вильда, предполагающий обязательное прохождение прямой через начало координат. (Метод Вильда предполагает равенство коэффициентов вариации годового стока в обоих пунктах, что для рек Эстонской ССР не всегда имеет место. Так, например, для реки Кейла $C_{v}=0,39$, а для реки Выханду $C_{v}=0,27$.)

Применение других аналитических методов, таких как нахождение корреляционных уравнений связи стока по отдельным станциям, требующее значнтельной вычислительной работы, как указывает Д. Л. Соколовский $\left({ }^{4}\right)$, не оправдывается увеличением точности результатов уже хотя 

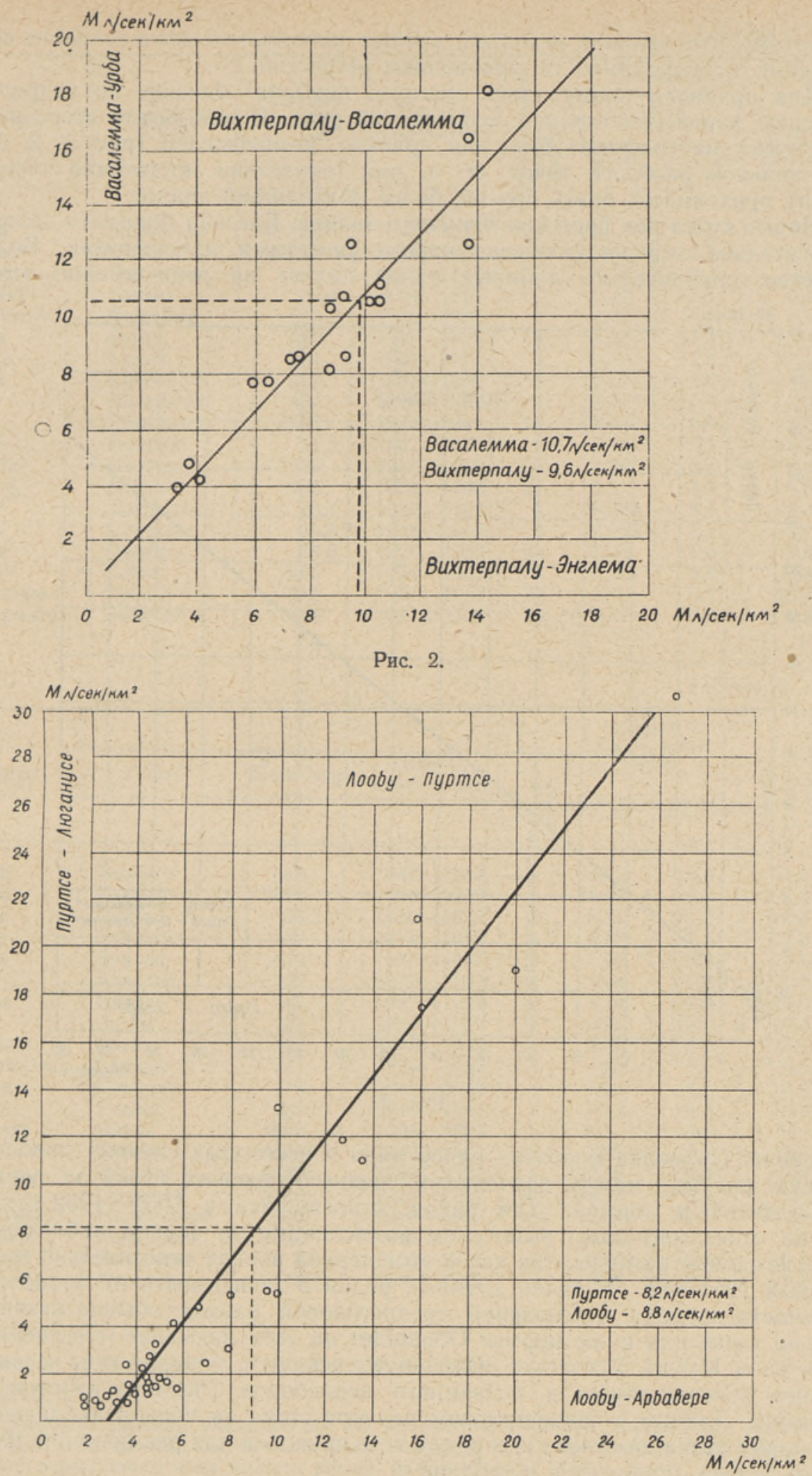

Рис. 3. 
бы потому, что точность исходных данных значительно ниже точности вычислений, пронзводимых по, уравнениям регрессии.

Для приводки применялись аналоги, наиболее близкие по гидрологическим характеристикам к исследуемой реке. В результате этого разброс точек на графиках был, как правило, незначителен (рис. 1, 2, 3). При сильном разбросе точек (т. е. при отсутствии достаточно тесной связи) приходилось брать другой, более подходящий аналог.

Норма стока рек бассейна Финского залива. Бассейн Финского залива относительно хорошо освещен гидрометрическими измерениями. Большинство сравнительно длинных рядов падает на реки именно этого

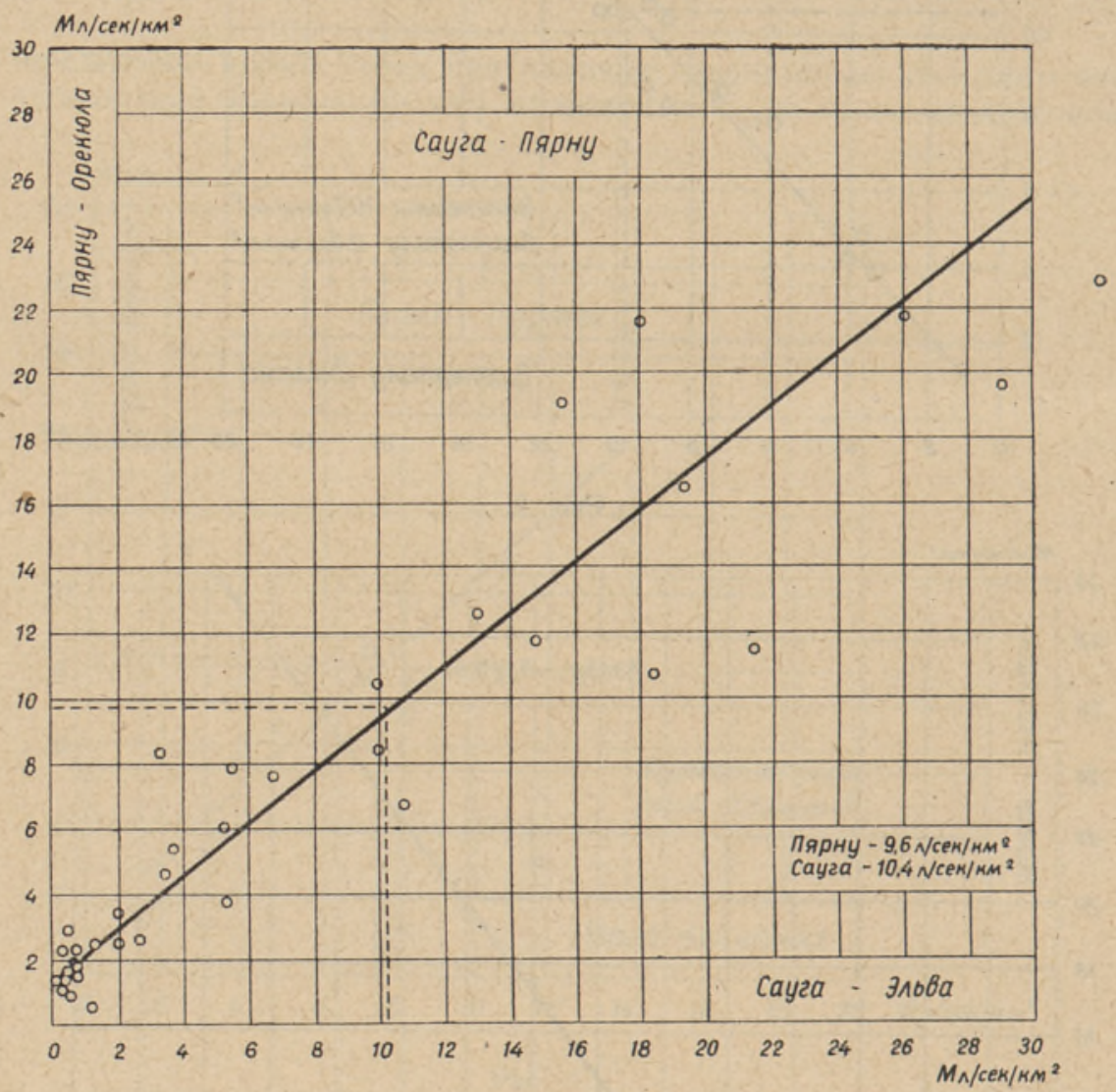

Рис. 4.

бассейна. Приводка коротких рядов дала в некоторых с̊лучаях довольно резкую разницу между значениями среднего годового стока за период наблюдений и нормой. Для рядов, относящихся к 1950-1952 годам, норма стока несколько выше, чем вычисленные за период наблюдений среднегодовые расходы, так как в этот период входит относительно маловодный 1951 год. У более длинных рядов в зависимости от продолжительности периода наблюдений среднегодовой расход обычно незначительно выше или ниже нормы. Обращает на себя внимание повышенный сток реки Кунда. Указанное явление объясняется, повидимому, несовпадением поверхностного и подземного водосборов (питание карстовыми водами). Данные о среднегодовом размере стока за пернод наблюдений и о норме стока, полученной в результате приводки для рек бассейна Финского залива, приводятся в таблице 5 . 
Таблица 5

\begin{tabular}{|c|c|c|c|c|c|c|c|}
\hline \multirow{2}{*}{ Река } & \multirow{2}{*}{ Створ } & \multirow{2}{*}{$\begin{array}{c}\text { Площадь } \\
\text { водосбора } \\
\text { км² }^{2}\end{array}$} & \multirow{2}{*}{$\begin{array}{c}\text { Период } \\
\text { наблюденин }\end{array}$} & \multirow{2}{*}{ 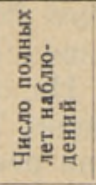 } & \multicolumn{2}{|c|}{$\begin{array}{c}\text { Средний за } \\
\text { период наблю- } \\
\text { дений }\end{array}$} & \multirow{2}{*}{ 뚤 } \\
\hline & & & & & $\begin{array}{l}\text { pacxoд } \\
\mathrm{M}^{3 / c e k}\end{array}$ & $\begin{array}{c}\text { модуль } \\
\pi / \text { сек.км² }^{2}\end{array}$ & \\
\hline Нарва & Васкнарва & 47800 & $1903-1952$ & 38 & 346 & 7,2 & 7,2 \\
\hline Нарва & Кулгу & 55900 & $1903-1952$ & 46 & 400 & 7,2 & 7,2 \\
\hline Пуртсе & Люганусе & 792 & $1923-1952$ & 27 & 6,50 & 8,2 & 8,2 \\
\hline Кирьяку & Нымме & 30,8 & $1948-1952$ & 5 & 0,27 & 8,7 & 9,5 \\
\hline Пюхайыги & Пюхайые & 166 & $1946-1952$ & 7 & 1,52 & 9,1 & 8,9 \\
\hline Кунда & Сями & 390 & $1947-1952$ & 6 & 4,20 & 10,8 & 11,4 \\
\hline Сельге & Аркна & 364 & $1948-1952$ & 3 & 2,69 & 7,4 & 8,3 \\
\hline Лообу & Арбавере & 202 & $1950-1952$ & 3 & 1,77 & 8,8 & 8,8 \\
\hline Валге & Ванакюла & 402 & $1949-1952$ & 3 & 3,10 & 7,7 & 9,7 \\
\hline Ягала & Линнамяэ & 1582 & $1924-1940$ & 14 & 12,72 & 8,0 & 7,6 \\
\hline Аавоя & Маапаю & 31,5 & $1942-1952$ & 9 & 0,29 & 9,1 & 8,3 \\
\hline Пирита & Паункюла & 119 & $1941-1952$ & 10 & 0,99 & 8,4 & 8,4 \\
\hline Пирита & Лагеди & 675 & $1928-1943$ & 16 & 5,9 & 8,7 & 9,8 \\
\hline Лейва & Арувалла & 10,4 & $1949-1952$ & 3 & 0,084 & 8,1 & 8,4 \\
\hline Лейва & Суурсоо & 20,6 & $1949-1952$ & 3 & 0,187 & 9,1 & 8,7 \\
\hline Лейва & Паюба & 84,3 & $1928-1952$ & 23 & 0,72 . & 8,5 & 8,8 \\
\hline Кейла & Кейла & 665 & $1924-1952$ & 26 & 6,25 & 9,4 & 9,4 \\
\hline Васалемма & Урба & 383 & $1931-1952$ & 22 & 3,71 & 9,7 & 10,7 \\
\hline Вихтерпалу & Энглема & 468 & $1931-1952$ & 19 & 3,97 & 8,5 & 9,6 \\
\hline
\end{tabular}

Таблица 6

\begin{tabular}{|c|c|c|c|c|c|c|c|}
\hline \multirow{2}{*}{ Река } & \multirow{2}{*}{ Створ } & \multirow{2}{*}{$\begin{array}{c}\text { Площадь } \\
\text { водосбора } \\
\text { км² }^{2}\end{array}$} & \multirow{2}{*}{$\begin{array}{c}\text { Период } \\
\text { наблюдений }\end{array}$} & \multirow{2}{*}{ 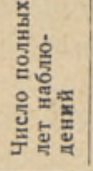 } & \multicolumn{2}{|c|}{$\begin{array}{c}\text { Средний за } \\
\text { пернод наблю- } \\
\text { дений }\end{array}$} & \multirow{2}{*}{ 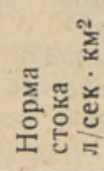 } \\
\hline & & & & & $\begin{array}{l}\text { pacxoд } \\
\mathrm{M}^{3} / \mathrm{cek}\end{array}$ & $\begin{array}{c}\text { модуль } \\
\text { л/сек, } \text { KM }^{2}\end{array}$ & \\
\hline Касари & Тээнусе & 649 & $1949-1952$ & 5 & 6,85 & 10,6 & 10,1 \\
\hline Касари & Касари & 2660 & $1948-1952$ & 5 & 24,86 & & 9,8 \\
\hline Вигала & Рапла & 53,2 & $1950-1952$ & 3 & 0,63 & 11,3 & 10,8 \\
\hline Вигала & Коновере & 558 & $1949-1952$ & 4 & 6,42 & 11,5 & 11,0 \\
\hline Велисе & Вянгла & $882^{*}$ & $1949-1952$ & 4 & 7,10 & 8,0 & 8.6 \\
\hline Энге & Ядивере & 132 & $1949-1952$ & 4 & 1,34 & 10,2 & 10,0 \\
\hline Вяндра & Кийса & 243 & $1947-1952$ & 6 & 2,14 & 8,9 & 10,0 \\
\hline Cayra & Эльби & 93 & $1950-1952$ & 3 & 0,95 & 10,2 & 10,4 \\
\hline Навести & Аэсоо & 957 & $1949-1952$ & 4 & 9,48 & 9,9 & 10,0 \\
\hline Леммийыги & Сандра & 211 & $1948-1952$ & 5 & 1,94 & 9,2 & 9,6 \\
\hline Раудна & Солгути & 719 & $1949-1952$ & 4 & 5,84 & 8,1 & 10,2 \\
\hline Кыпу & Римму & 265 & $1946-1952$ & 7 & 2,11 & 8,0 & 10,0 \\
\hline Халлисте & Рийса & 1920 & $1948-1952$ & 5 & 16,3 & 8,5 & 9,4 \\
\hline Рейю & Сурью & 349 & $1948-1952$ & 5 & 2,82 & 8,1 & 8,6 \\
\hline Пярну & Тахкусе & 2120 & $1949-1952$ & 4 & 19,66 & 9,3 & 9,8 \\
\hline Пярну & Орекюла & 5180 & $1922-1952$ & 89 & 49,75 & 9,6 & 9,6 \\
\hline Паадремаа & Мытсуснлла & 216 & $1948-1952$ & 5 & 2,34 & 10,8 & 10,8 \\
\hline Мустйыги & Коннувере & 1220 & $1945-1952$ & 8 & 8,29 & 6,8 & 8,3 \\
\hline Валуоя & Вильянди & 3,9 & $1949-1952$ & 3 & 0,041 & 10,5 & 10,1 \\
\hline Пээглеоя & Куустле & 44,9 & $1946-1952$ & 7 & 0,36 & 8,2 & 8,4 \\
\hline Пунапеа & Метскюла & 101 & $\begin{array}{l}\text { Ост р в а } \\
1946-1952\end{array}$ & 7 & 0,72 & 7,1 & 9,6 \\
\hline
\end{tabular}

* Имеются данные, указывающие на наличие ошибки при определении площади

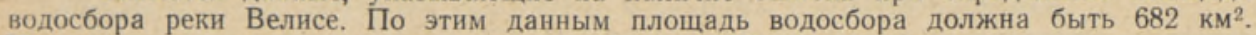

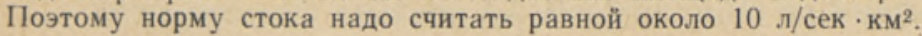


Норма стока рек бассейна Рижского залива. Наиболее слабо освещенным в гидрометрическом отношении оставался до последнего времени бассейн Рижского залива. Длительные наблюдения имеются здесь только по одной реке Пярну. На остальных реках бассейна продолжительность наблюдений не превышает 7 лет (по состоянию на 1 I 1953). Отсутствие достаточного количества рек, могущих служить аналогами для приводки, заставило использовать, кроме реки Пярну, реки бассейна Финского залива - Вихтерпалу, Васалемма и реки бассейна Чудского озера Вяйке Эмайыги и Суур Эмайыги в тех случаях, когда наблюдалась достагочно тесная связь в ходе годового стока между аналогом и рассматриваемой рекой.

Результаты приводки даны в таблице 6 .

Норма стока рек бассейна Чудского озера. Результаты приводки для рек бассейна Чудского озера даны в таблице 7.

Таблица 7

\begin{tabular}{|c|c|c|c|c|c|c|c|}
\hline \multirow{2}{*}{ Река } & \multirow{2}{*}{ Створ } & \multirow{2}{*}{$\begin{array}{c}\text { Площадь } \\
\text { водосбора } \\
\text { км² }^{2}\end{array}$} & \multirow{2}{*}{$\begin{array}{c}\text { Период } \\
\text { наблюдений }\end{array}$} & \multirow{2}{*}{ 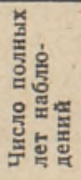 } & \multicolumn{2}{|c|}{$\begin{array}{c}\text { Средний за } \\
\text { пернод наблю- } \\
\text { дений }\end{array}$} & \multirow{2}{*}{ 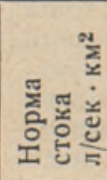 } \\
\hline & & & & & $\underset{M^{3} / \text { ceK }^{\text {pacxod }}}{ }$ & $\begin{array}{c}\text { модуль } \\
\text { л/сек·км² }\end{array}$ & \\
\hline $\begin{array}{l}\text { Вяйке Эмайыги } \\
\text { Суур Эмайыги } \\
\text { Педья } \\
\text { Паала } \\
\text { Ыхне } \\
\text { Ахья } \\
\text { Выханду } \\
\text { Пийгасте оя } \\
\text { Эльва }\end{array}$ & $\begin{array}{l}\text { Тыллисте } \\
\text { Тарту } \\
\text { Тырве } \\
\text { Пыльтсама } \\
\text { Тырва } \\
\text { Коорвере } \\
\text { Химмисте } \\
\text { Пийгасте } \\
\text { Эльва }\end{array}$ & $\begin{array}{c}1070 \\
7850 \\
792 \\
1000 \\
270 \\
286 \\
853 \\
14,3 \\
246\end{array}$ & $\begin{array}{l}1922-1952 \\
1903-1952 \\
1929-1952 \\
1950-1952 \\
1950-1952 \\
1948-1952 \\
1924-1952 \\
1949-1952 \\
1948-1952\end{array}$ & $\begin{array}{r}28 \\
35 \\
20 \\
3 \\
3 \\
5 \\
26 \\
4 \\
5\end{array}$ & $\begin{array}{r}8,77 \\
58,67 \\
5,86 \\
9,72 \\
2,03 \\
2,13 \\
6,76 \\
0,09 \\
1,98\end{array}$ & $\begin{array}{l}8,2 \\
7,5 \\
7,4 \\
9,7 \\
7,5 \\
7,4 \\
7,9 \\
6,3 \\
8,0\end{array}$ & $\begin{array}{l}8,2 \\
7,5 \\
7,8 \\
8,4 \\
9,0 \\
8,6 \\
7,9 \\
7,6 \\
8,3\end{array}$ \\
\hline
\end{tabular}

Полученные в результате приводки значения нормы стока для отдельных бассейнов дают возможность более точно производить гидрологические расчеты в различных областях водного хозяйства Эстонской ССР и в дальнейшем послужат дополнительным материалом для составления более детальной карты нормы стока.

Ннститут мелиорации и освоения осушенных земель Академии наук Эстонской ССР
Поступнла в редакцию 17 XII 1954

\section{ЛИТЕРАТУРА}

1. Б. Д. 3 а й ко в и С. Ю. Б ел и н ко в, Норма годового стока, ее погрешность и приведение коротких рядов к длительному периоду, «Исследование рек СССР», вып. X, 1936.

2. Э. М. О льдек оп, Об испарении с поверхности речных бассейнов, Юрьев, 1911.

3. Д. Л. С околовски й, Гидрологические и водохозяйственные расчеты при проектировании малых ГЭС, Гидрометеоиздат, Л., 1946.

4. Д. Л. С около в ски й, Речной сток, Гидрометеоиздат, Л., 1952.

5. Sisevete Uurimise Aastaraamat 1930-1932, Tallinn 1934. 